SHORT REPORT

\title{
A study of the workload and effectiveness of a comprehensive acute stroke service
}

\section{N U Weir, A M Buchan}

Objective: To study the workload of and use of acute intervention within an established acute stroke service, the Calgary Stroke Programme (CSP).

Methods: Prospective record of all acute referrals, diagnoses, and management decisions over a 4 month period. Results: The CSP received 572 referrals (median: 32 per week), $88 \%$ of which were made between $7 \mathrm{am}$ and midnight. Of the 427 patients seen in person, $29 \%$ had not had an acute stroke or transient ischaemic attack (TIA). Fifty percent of patients with suspected acute stroke were referred within $3 \mathrm{~h}$ of symptom onset and $11 \%$ with acute ischaemic stroke lequating to $35 \%$ of those referred within $3 \mathrm{~h}$ of onset and seen in person) were treated with thrombolysis.

Conclusion: Centralisation of services facilitates the rapid referral of, and use of acute interventions in, patients with acute stroke and TIA. Centralised services are likely to be busy (although less so at night), to attract large numbers of patients with disorders that mimic stroke and TIA, and yet still likely to treat only the minority of acute strokes using thrombolysis. These observations may help those planning similar services and underline the need to develop more widely applicable treatments for acute stroke.

A cute stroke and transient ischemic attack (TIA) demand a rapid response. Thrombolysis must be given within $3 \mathrm{~h}$ of onset of acute ischaemic stroke (AIS) ${ }^{1}$ and the high risk of early recurrence after TIA or minor stroke argues for immediate secondary prevention. ${ }^{2-4}$ However, providing acute interventions for large numbers of patients with stroke or TIA requires both public education (about symptoms and the need to present quickly) and the reorganisation of ambulance and hospital services, and is a considerable undertaking. ${ }^{56}$ A cost effective approach to service delivery might be to concentrate resources and expertise for a given population within a single hospital. ${ }^{7}$ Established in 1996, the Calgary Stroke Programme (CSP) is a mature example of such a centralised and specialised acute stroke service. The purpose of this study was to document its workload and effectiveness in order to help guide the planning of similar services.

\section{METHODS}

The CSP serves a population of about 1.4 million, and, within Calgary, is the single point of referral for adults with suspected acute stroke or TIA, regardless of age. The acute stroke team comprises a trainee stroke physician and a consultant stroke neurologist. All acute referrals are made by telephone call to the acute stroke pager, held by the on-call stroke clinician, who triages patients to:

- immediate assessment: cases within $6 \mathrm{~h}$ of onset of possible acute stroke (plus selected cases a few hours after this) and all cases within $24 \mathrm{~h}$ of possible "high risk" (motor or language) TIA, ${ }^{3}$

- assessment at the CSP clinic (within days): cases with a less recent or probable "low risk" TIA, ${ }^{3}$ or

- assessment by the acute neurology service: cases with stroke outside the CSP parameters or unlikely to have an acute stroke.

Referrals come from emergency room physicians, ambulance crews (who are not required to differentiate hyperacute TIA from stroke), hospital physicians, and family practitioners. Immediate assessment entails rapid interview, examination, and head imaging. Patients with disabling ischaemic stroke within $3 \mathrm{~h}$ of onset are offered intravenous (IV) thrombolysis. Intra-arterial (IA) thrombolysis is offered to selected patients presenting after this time and/or in certain clinical situations. Patients with high risk TIA are admitted to hospital to expedite investigation and secondary prevention.

We kept a prospective log of all acute referrals, diagnoses, and management decisions in the first $24 \mathrm{~h}$ over a 4 month period (January to May 2004). We calculated the proportion treated with thrombolysis conservatively by including both probable stroke (patients diagnosed in person or in whom telephone consultation strongly suggested stroke) and possible stroke (patients without a clear working diagnosis in whom stroke was queried) in the denominator. For calculations limited to AIS, we assumed all possible and uncategorised strokes were ischaemic. We used the $\kappa$ statistic $^{8}$ to assess agreement between the referrer and the CSP on the interval from onset to referral ( $<3 \mathrm{~h} v \geqslant 3 \mathrm{~h}$, etc) and restricted this analysis to patients with a verified time of onset (that is, those seen in person).

\section{RESULTS}

The CSP received a total of 572 referrals (433 for suspected stroke and 139 for suspected TIA) with a median of 32 per week (range 22-53). Most referrals (88\%) were made between $7 \mathrm{am}$ and midnight. Referrals came from: emergency rooms in and outside Calgary $(51 \%$ and $12 \%$, respectively); ambulance crews (24\%); hospital physicians $(9 \%)$; primary physicians $(3 \%)$; and others $(1 \%)$.

Fifty percent of patients $(\mathrm{n}=215)$ with suspected stroke were referred within $3 \mathrm{~h}$, and $63 \%(\mathrm{n}=273)$ within $6 \mathrm{~h}$, of onset, while $72 \%(n=96)$ with suspected TIA were referred within $12 \mathrm{~h}$ of onset. Agreement between referrers and the CSP on these intervals was good $(\kappa=0.79,0.69,0.82$, respectively). For acute stroke, where there was disagreement, the referrer systematically under-estimated the delay (verified delay $<3$ h $v \geqslant 3$ h: referral data agreed, $\mathrm{n}=155$;

Abbreviations: AIS, acute ischaemic stroke; CSP, Calgary Stroke Programme; IA, intra-arterial; IV, intravenous; TIA, transient ischaemic attack 
Table 1 Diagnosis in the 125 patients who did not have an acute stroke or TIA

\begin{tabular}{lc}
\hline Diagnosis & $\%$ \\
\hline Seizure/post-ictal & 19 \\
Migraine & 15 \\
Functional disorder & 14 \\
Metabolic disturbance & 8 \\
Syncope/pre-syncope & 6 \\
Infection & 6 \\
Cerebral mass: tumour or subdural haematoma & 5 \\
Peripheral vestibular disturbance & 3 \\
Multiple sclerosis related & 3 \\
Spinal/radicular/peripheral nerve problem & 3 \\
Confusion: various or undefined causes & 6 \\
Miscellaneous other diagnoses/not recorded & 12 \\
\hline
\end{tabular}

under-estimated, $\mathrm{n}=18$; over-estimated, $\mathrm{n}=0$; no data, $\mathrm{n}=10$ ).

The CSP dealt with $25 \%(\mathrm{n}=145)$ of referrals by telephone only: $48 \%$ of these were redirected to acute neurology and $32 \%$ to the CSP clinic, and $20 \%$ of referrers were given advice. The working diagnoses in these cases were: AIS $(n=40)$; intracerebral haemorrhage $(\mathrm{n}=4)$; TIA $(\mathrm{n}=24)$; uncertain (stroke $v$ other, $\mathrm{n}=26$; TIA $v$ other, $\mathrm{n}=28$ ); and not stroke $(\mathrm{n}=23)$.

The CSP assessed $75 \%(n=427)$ of referrals in person and diagnosed acute stroke (150 infarcts, 31 haemorrhages, one venous infarct, one uncategorised) or TIA $(n=88)$ in $64 \%$ of cases. Non-stroke diagnoses were made in $29 \%(n=125$; see table 1) and no clear working diagnosis was reached in $7 \%$ (stroke $v$ other, $\mathrm{n}=17$; TIA $v$ other, $\mathrm{n}=14$ ). Similar results applied regardless of the referral diagnosis or source, except for cases from emergency rooms outside Calgary (78\% were stroke or TIA).

IV thrombolysis was used in 19 patients, IV followed by IA thrombolysis in two patients, and IA thrombolysis alone in five patients. The proportion with any acute stroke treated by thrombolysis was $10 \%(26 / 270)$. The proportion with AIS treated by thrombolysis was $11 \%(26 / 232)$, equating to $17 \%$ $(26 / 150)$ of those with AIS seen in person and 35\% (24/67) of those also referred within $3 \mathrm{~h}$ of onset (see table 2 ). Eighty six percent of patients with TIA seen in person (76/88) were admitted to hospital.

\section{DISCUSSION}

This study makes four points regarding the provision of an acute stroke service. First, it confirms that, along with public education, centralisation and organisation of services allows large numbers of patients to be assessed within hours of symptom onset and acute interventions to be used in a much larger proportion than is possible under a traditional system of care. ${ }^{90}$ The low threshold of the Calgary public for involving the emergency services when they suspect a stroke clearly underlies much of the CSP's success in attracting early referrals $^{5}$ (data from our stroke register suggest the median interval from stroke onset to hospital arrival is $137 \mathrm{~min}$; inter-quartile range 60-358 $\mathrm{min}$ ).

Second, it shows that a centralised service is likely to be busy and potentially active $24 \mathrm{~h}$ per day. Given that the population of Calgary is relatively young (9\% aged 65 or above), services for more elderly populations are likely to be busier still ( $16 \%$ of the UK population are aged 65 or above). However, $88 \%$ of referrals occurred between $7 \mathrm{am}$ and midnight, in keeping with the diurnal variation in stroke incidence. ${ }^{11}$ Where resources are limited it would seem sensible to concentrate services over this period. Similarly, since referrers seem rarely to over-estimate the interval from onset, triage of patients reported to be outside treatment time windows to less acute services is likely to be safe.

Third, it shows that an acute service is likely to attract large numbers with non-stroke conditions. Our estimate that $29 \%$ of referrals were stroke mimics is high in comparison with some studies ${ }^{12}{ }^{13}$ but not others. ${ }^{14}{ }^{15}$ Our high stroke-mimic rate may reflect: the difficulty of excluding stroke on the basis of a single and rapid clinical examination; the difficulty of diagnosing acute TIA $^{16}$; a low threshold for referring "possible" cases for fear of missing some who might benefit from intervention; the high number of referrals direct from ambulance crews ${ }^{14}{ }^{17}$ (despite use of a stroke recognition instrument ${ }^{18}$ ); the play of chance (the lower $95 \%$ confidence limit for stroke-mimics was 25\%); and the possibility of overdiagnosis on our part (we did not follow cases beyond $24 \mathrm{~h}$ ). The differentiation of AIS from its mimics must be done without the help of a simple test analogous to the ECG and can be difficult in the hyper-acute setting. Given the nontrivial complications of thrombolytic therapy, the task should be led by clinicians with appropriate training and expertise.

Fourth, it shows that even within a specialised system of care only a minority with AIS are treated with thrombolysis, either because the majority present too late or for various reasons (for example, rapid improvement, mild deficit, etc) are judged unlikely to benefit. ${ }^{19}$ This observation underlines the need for on-going efforts to educate the public and to optimise ambulance and hospital responses, even when a service is well established. It also highlights the urgent need to develop more widely applicable treatments for acute stroke, although there are reasons to be optimistic. ${ }^{120-23}$

The main limitation of this study is that we did not follow patients beyond $24 \mathrm{~h}$ and therefore some of our working diagnoses might later have been overturned. For the same reason, we have been unable to give a final diagnosis in patients triaged to other services (and so cannot comment on its appropriateness) nor say what proportion without a clear working diagnosis actually had a stroke or TIA. In general, however, these biases are likely to be small (all patients seen in person were assessed by a consultant and had cranial imaging) and we used conservative methods to mitigate their impact. Moreover, by concentrating on the first $24 \mathrm{~h}$, our findings reflect the realities and uncertainties of treating patients with hyper-acute stroke and TIA. Our findings are therefore likely to remain useful to those planning similar systems of care.

Table 2 Numbers needed in order to treat (NNT) one patient with an AIS with thrombolytic therapy

\begin{tabular}{lc} 
& NNT \\
\hline Referrals (for possible stroke or TIA) to the acute stroke pager $(n=572)$ & 22 \\
Referrals (for possible stroke or TIA) seen in person $(n=427)$ & 16 \\
Patients with a probable acute stroke (assessed in person or by telephone) $(n=270)$ & 10 \\
Patients with confirmed acute stroke seen in person $(n=183)$ & 7 \\
Patients with confirmed AIS seen in person $(n=150)$ & 6 \\
Patients with confirmed AIS referred $<3$ from onset, seen in person $(n=67)$ & 3 \\
\hline
\end{tabular}




\section{ACKNOWLEDGEMENTS}

We would like to thank all the members of the Calgary Stroke Programme who recorded their activity as part of this project and Dr Michael Hill for providing data from our hospital stroke register.

\section{CONTRIBUTIONS}

NUW designed the study, collected and analysed the data, and cowrote the manuscript. AMB conceived the study, helped with its design, and co-wrote the manuscript.

\section{Authors' affiliations}

N U Weir, A M Buchan, Department of Clinical Neurosciences, University of Calgary, Canada

This project has not received any specific funding. However, the research work of the Calgary Stroke Programme is supported by the Canadian Institutes of Health Research, the Alberta Heritage Foundation for Medical Research, the Canadian Stroke Network, the Canadian Stroke Consortium, and the Heart and Stroke Foundation of Canada.

Competing interests: none declared

We did not seek ethical approval prior to this study because our study related only to an audit of our activity and because the data we collected were entirely anonymous.

Correspondence to: Dr N U Weir, Room 1211, Foothills Medical Centre, 1403-29th Street NW, Calgary, Canada T2N 2T9; nicweir@ hotmail.com

Received 7 September 2004

Revised version received 17 November 2004

Accepted 18 November 2004

\section{REFERENCES}

1 Wardlaw JM, del Zoppo G, Yamaguchi T, et al. Thrombolysis for acute ischaemic stroke. Cochrane Stroke Group. Cochrane Database Syst Rev 2004:(2):CD000213.

2 Coull AJ, Lovett JK, Rothwell PM, on behalf of the Oxford Vascular Study. Population based study of early risk of stroke after transient ischemic attack or minor stroke: implications for public education and organization of services. BMJ 2004;328:326-8.

3 Johnston SC, Gress DR, Browner WS, et al. Short-term prognosis after emergency department diagnosis of TIA. JAMA 2000;284:2901-6.
4 Rothwell PM, Eliasziw M, Gutnikov SA, et al. for the Carotid Endarterectomy Trialists Collaboration. Endarterectomy for symptomatic carotid stenosis in relation to clinical subgroups and timing of surgery. Lancet 2004;363:915-24.

5 Kwan J, Hand P, Sandercock P. A systematic review of barriers to delivery of thrombolysis for acute stroke. Age Ageing 2004;33:1 16-21.

6 Hill MD, Barber PA, Demchuk AM, et al. Building a "brain attack" team to administer thrombolytic therapy for acute ischemic stroke. CMAJ 2000;162:1589-93

7 Riopelle RJ, Howse DC, Bolton C, et al. Regional access to acute ischemic stroke intervention. Stroke 2001;32:652-5.

8 Brennan P, Silman A. Statistical methods for assessing observer variability in clinical measures. BMJ 1992;304:1491-4.

9 Morgenstern LB, Staub L, Chan W, et al. Improving delivery of acute stroke therapy. The TLL Temple Foundation stroke project. Stroke 2002;33:160-6.

10 Reed SD, Cramer SC, Blough DK, et al. Treatment with tissue plasminogen activator and inpatient mortality rates for patients with ischemic stroke treated in community hospitals. Stroke $2001 ; 32$ : 1832-40.

11 Elliott WJ. Circadian variation in the timing of stroke onset. A meta-analysis. Stroke 1998;29:992-6.

12 Ferro JM, Pinto AN, Falcao I, et al. Diagnosis of stroke by the non-neurologist. A validation study. Stroke 1998;29:1106-9.

13 Kothari RU, Brott T, Broderick JP, et al. Emergency physicians. Accuracy in the diagnosis of stroke. Stroke 1995;26:2238-41.

14 Harbison J, Hossain O, Jenkinson D, et al. Diagnostic accuracy of stroke referrals from primary care, emergency room physicians, and ambulance staff using the Face Arm Speech Test. Stroke 2003;34:71-6.

15 Moulin T, Sablot D, Vidry E, et al. Impact of emergency room neurologists on patient management and outcome. Eur Neurol 2003;50:207-14.

16 Ferro JM, Falcao I, Rodrigues G, et al. Diagnosis of transient ischemic attack by the nonneurologist. A validation study. Stroke 1996;27:2225-9.

17 Kothari R, Barsan W, Brott T, et al. Frequency and accuracy of prehospital diagnosis of acute stroke. Stroke 1995;26:937-41.

18 Kidwell CS, Starkman S, Eckstein M, et al. Identifying stroke in the field. Prospective validation of the Los Angeles Prehospital Stroke Screen (LAPSS) Stroke 2000;31:71-6.

19 Barber PA, Zhang J, Demchuk AM, et al. Why are stroke patients excluded from TPA therapy? An analysis of patient eligibility. Neurology 2001;56:1015-20.

20 NovoSeven Intracerebral Hemorrhage (ICH) Trial (http://www. strokecenter.org/trials/TrialDetail.asp?ref = 431) (accessed Sept 2004)

21 The ATLANTIS, ECASS, and NINDS rt-PA Study Group Investigators. Association of outcome with early stroke treatment: pooled analysis of ATLANTIS, ECASS, and NINDS rt-PA stroke trials. Lancet 2004;363:768-74.

22 Desmoteplase in Acute Ischemic Stroke (DIAS) trial (http://www. strokecenter.org/trials/TrialDetail.asp?ref = 371) (accessed Sept 2004).

23 Furlan A, Higashida R, Wechsler L, et al. Intra-arterial prourokinase for acute ischemic stroke. The PROACT II study: a randomized controlled trial. JAMA 1999;282:2003-11. 